Gut, 1978, 19, 754-758

\title{
Response of the skin in dermatitis herpetiformis to a gluten free diet, with reference to jejunal morphology
}

\author{
B. T. COOPER, E. MAllas, M. D. TROTter, AND W. T. COOKE \\ From the Nutritional and Intestinal Unit, General Hospital, Birmingham and the MRC Unit on the \\ Experimental Pathology of the Skin, University of Birmingham, Birmingham
}

SUMMARY Twenty-one patients with dermatitis herpetiformis have been on a gluten free diet and regularly followed up for at least one year (mean four years). Eighteen patients had a 'flat' mucosal appearance (grade III), one patient had moderately severe mucosal abnormality (grade II), one patient had mild mucosal abnormality (grade I), and one patient had a normal mucosal appearance (grade 0). On the diet, 10 patients had no skin rash and took no dapsone, seven patients controlled the skin rash on a lower dose of dapsone, and four noticed no improvement. There was no correlation between pre-diet jejunal morphology and response of the skin. A repeat jejunal biopsy, on the gluten free diet, was possible in 15 patients. While all those with skin improvement showed some improvement in jejunal morphology, there was no association between the degree of skin improvement and the degree of recovery of the jejunal mucosa.

Following the work of Marks et al. (1966), dermatitis herpetiformis (DH) is recognised as being associated with a high incidence of abnormality in the jejunal mucosa which is identified with that of coeliac disease (Brow et al., 1971) and which improves morphologically with gluten withdrawal from the diet (Fry et al., 1968, 1969; Shuster et al., 1968; Marks and Whittle, 1969; Weinstein et al., 1971; Fry et al., 1972). The skin rash also is claimed by Fry et al. (1973) and by Heading et al. (1976) to show improvement but this is doubted by Marks and Shuster (1970), Weinstein et al. (1971), and by Marks (1974). A point considered in detail only by Fry et al. (1969) is the state of the jejunal mucosa in relation to the response of the skin lesion while on a gluten free diet. The purpose of this paper therefore is to repeat such studies.

\section{Methods}

PATIENTS

Twenty-one patients, 12 female and nine males, varied in age from 16 to 58 years (mean 37 years) at the time of diagnosis of dermatitis herpetiformis. The length of history of the disorder to its diagnosis

Received for publication 17 February 1978 ranged from two months to 21 years (mean 51 years) and the time of follow-up from diagnosis to the start of a gluten free diet ranged from one month to 17 years (mean 4 years). None of the patients in this series was related, but two patients (one male, one female) had first-degree relatives with biopsy proven coeliac disease, but no dermatitis herpetiformis. All patients were alleged to have been on a strict diet for at least 12 months and in one case 10 years (mean four years). The patients in this series were unselected except by their willingness to adhere to a strict gluten free diet. Each patient has been regularly followedup in the Nutritional and Intestinal Unit while on the gluten free diet.

DIAGNOSIS OF DERMATITIS HERPETIFORMIS

The diagnosis was based on the characteristic intensely irritating vesicular eruption sited symmetrically on elbows, exterior surfaces of arms, scapular area, scalp, buttocks, and the front of the knees, together with rapid clearance of the skin lesions with dapsone. Any patient with an atypically distributed rash or a rash which did not rapidly resolve with dapsone was excluded even if they had coeliac disease. Eleven patients had biopsies taken of the vesicles, the histology of which was compatible with dermatitis herpetiformis. Twenty of the 21 patients had uninvolved skin biopsied from the 
thigh and stained for $\operatorname{IgA}$ deposits using direct immunofluoresence (Seah et al., 1972).

\section{JEJUNAL BIOPSIES}

Peroral jejunal biopsy, using a multiple biopsy capsule (Roy-Choudhury et al., 1964), was performed on each patient before starting on a gluten free diet, obtaining between two and five specimens at a time and each invariably much larger than the single specimens obtained by a Crosby capsule. The resulting specimens were examined by dissecting microscopy; $5 \mu$ sections of each piece of jejunum were cut and stained with haematoxylin and eosin for histological examination and for cell counting. Each biopsy obtained was graded from 0 to III using the classification of Roy-Choudhury et al. (1966) and the lamina propria and epithelial cellular infiltrate were counted using the technique of Holmes et al. (1974) and Ferguson et al. (1975). Jejunal biopsies were repeated in $\mathbf{1 5}$ patients after at least one year on a gluten-free diet. Five patients refused further jejunal biopsies and one patient was pregnant at the time of this study.

\section{ANTIRETICULIN ANTIBODIES}

The sera of 16 of the 21 patients were tested, while on the gluten free diet for the presence of IgG and IgA class antireticulin antibodies using the standard immunofluorescent technique (Seah et al., 1971).

\section{Results}

JEJUNAL HISTOLOGY

The classification of the jejunal histology and the mucosal and epithelial cell counts before and after a gluten free diet are detailed in Table 1 and the relationship of the improvement of the skin rash and the mucosal change in Table 2. There was no corre- lation between the skin response and the initial jejunal cell counts.

Of the six patients not rebiopsied, five had grade III and one grade II biopsies initially. One of the grade III patients was pregnant but the other five refused a repeat biopsy. Four of these patients (three grade III and one grade II) were entirely without skin or bowel symptoms and did not feel that a repeat biopsy was necessary. The remaining patient (grade III) had no bowel symptoms but still required a small dose of dapsone to control his rash and he too would not agree to a repeat biopsy.

\section{SKIN RESPONSE TO GLUTEN FREE DIET (Table 2)}

Currently, 10 patients have no skin rash and take no dapsone and, in seven patients, the rash has greatly improved on the diet, requiring a much lower dose of dapsone. The mean daily dose of dapsone for these patients before the diet was $143 \mathrm{mg} /$ day whereas after at least one year on the diet it was $66 \mathrm{mg} /$ day (mean difference, $77 \mathrm{mg} /$ day $\pm 22 \mathrm{mg} /$ day; $\mathrm{N}=7$; $t=3.38 ; \mathrm{P}<0.02$ ). Four of the 21 patients have noticed no benefit to their skin whatsoever on the diet, including the patient with normal histology of jejunal mucosa.

TIME ON GLUTEN FREE DIET RELATED TO SKIN RESPONSE

Patients with no rash, who took no dapsone, had been on the diet for $1 \frac{1}{2}$ to $9 \frac{1}{2}$ years (mean $4 \frac{1}{2}$ years). Those with reduced dapsone requirements had been on the diet for $1 \frac{1}{2}$ to $7 \frac{1}{2}$ years (mean $4 \frac{1}{2}$ years). The non-responders have been on the diet for one to $2 \frac{1}{2}$ years (mean $2 \frac{1}{4}$ years).

IgA SKIN DEPOSITS AND SKIN RESPONSE (Table 2)

Ten of the 20 patients who were examined for the

Table 1 Jejunal biopsy morphology and cell counts on normal and gluten free diets

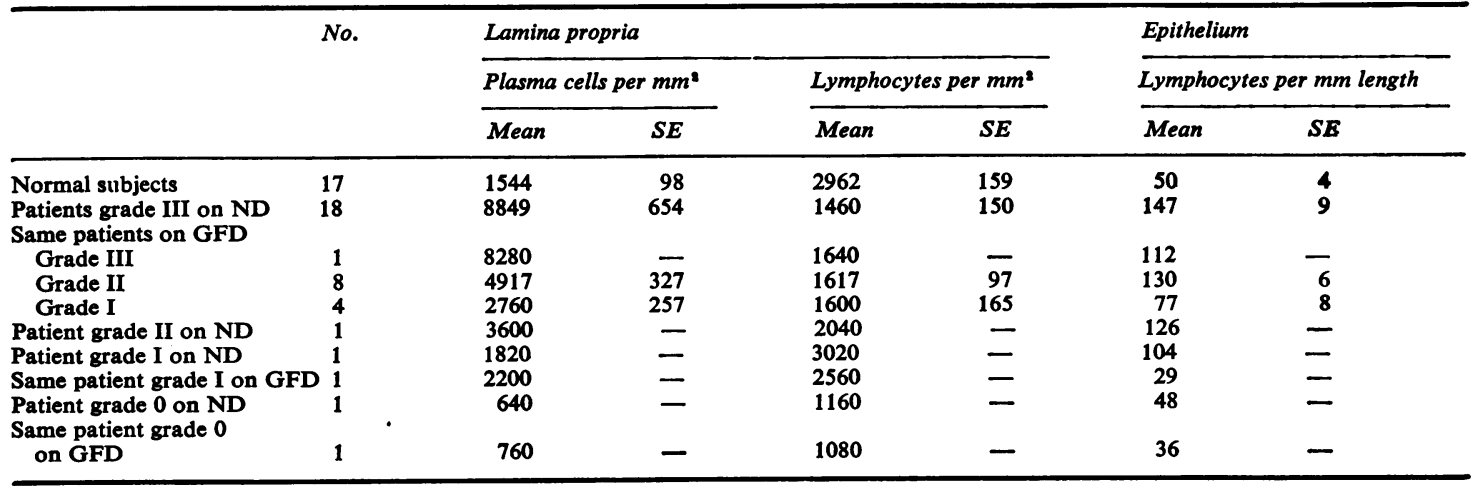

ND: normal diet. GFD: gluten free diet. 
Table 2 Improvement of skin rash and mucosal dosage

\begin{tabular}{|c|c|c|c|c|c|c|c|}
\hline \multirow[t]{2}{*}{ Case no. } & \multirow[t]{2}{*}{ Sex } & \multicolumn{2}{|c|}{ Jejunal biopsy grade } & \multirow[t]{2}{*}{ Skin response } & \multirow[t]{2}{*}{ Skin IgA } & \multicolumn{2}{|c|}{ Serum ARA } \\
\hline & & Initial & $G F D$ & & & $I g G$ & $\operatorname{IgA}$ \\
\hline 21 & $\mathbf{M}$ & III & ND & 1 & NEG & NEG & NEG \\
\hline 5 & $\mathbf{F}$ & III & ND & 1 & NEG & POS & NEG \\
\hline 6 & $\mathbf{F}$ & III & ND & 1 & POS & POS & NEG \\
\hline 11 & $\mathbf{M}$ & III & ND & $i$ & ND & ND & ND \\
\hline 15 & $\mathbf{M}$ & II & ND & 1 & POS & NEG & NEG \\
\hline 7 & $\mathbf{F}$ & III & I & 1 & POS & ND & ND \\
\hline 11 & $\mathbf{F}$ & III & I & 1 & NEG & POS & NEG \\
\hline 18 & $\mathbf{F}$ & III & I & 1 & NEG & NEG & NEG \\
\hline 4 & $\mathbf{F}$ & III & II & 1 & POS & NEG & NEG \\
\hline 10 & $\mathbf{F}$ & I & I & 1 & NEG & ND & ND \\
\hline 12 & $\mathbf{M}$ & III & ND & 2 & NEG & NEG & NEG \\
\hline 3 & $\mathbf{M}$ & III & I & 2 & POS & NEG & NEG \\
\hline 9 & $\mathbf{M}$ & III & I & 2 & POS & NEG & NEG \\
\hline 2 & $\mathbf{F}$ & III & II & 2 & NEG & NEG & NEG \\
\hline 6 & $\mathbf{M}$ & III & II & 2 & POS & NEG & NEG \\
\hline 8 & $\mathbf{F}$ & III & II & 2 & NEG & ND & ND \\
\hline 13 & $\mathbf{M}$ & III & II & 2 & POS & NEG & NEG \\
\hline 14 & $\mathbf{M}$ & III & II & 3 & NEG & ND & ND \\
\hline 19 & $\mathbf{F}$ & III & II & 3 & POS & POS & NEG \\
\hline 20 & $\mathbf{F}$ & III & III & 3 & NEG & POS & NEG \\
\hline 17 & $\mathbf{F}$ & 0 & 0 & 3 & POS & NEG & NEG \\
\hline
\end{tabular}

ND: not done.

1: no rash, no dapsone. 2: rash controlled, less dapsone. 3: no change. ARA: antireticulin antibodies. GFD: gluten free diet.

presence of IgA in areas of uninvolved skin, had a positive result ranging from an almost continuous line of deposit to an isolated patch on a single papilla. All 10 patients in whom IgA deposits were not found had the characteristic rash clearing rapidly with dapsone; four had vesicle biopsies consistent with dermatitis herpetiformis, and nine had a 'flat' jejunal mucosa. The patient with normal jejunal histology not responding to a gluten free diet but with a rapid response to dapsone had both a positive histological skin biopsy and IgA deposits in her uninvolved skin. The presence or absence of $\operatorname{IgA}$ skin deposits bore no relationship to the response of the skin rash or that of the jejunal mucosa to a gluten free diet.

\section{ANTIRETICULIN ANTIBODIES ON GLUTEN FREE DIET (Table 2)}

IgG class antireticulin antibodies were found in the serum of five patients but IgA class antireticulin antibodies were not found in any patients. The skin of three of the patients with a positive result showed an excellent response to a gluten free diet and two showed none, one showing improvement to grade II histology and the other improvement in cell count of the jejunal mucosa.

\section{Discussion}

Misdiagnosis is thought by Fry and Seah (1974) to be the explanation for the reported differences of response of the skin in dermatitis herpetiformis to a gluten free diet, for they consider that the presence of IgA deposits is essential for the diagnosis and also that the papillary pattern of $\operatorname{IgA}$ deposits in the skin occurs only in dermatitis herpetiformis (Seah and Fry, 1975). The specificity of these findings has been doubted by Marks (1974), Alexander (1975) and Scott et al. (1976) while Ross et al. (1977) found IgA deposits in the dermo-epidermal junction and/or dermal papillae in eight of 16 coeliac patients and in seven of 54 control subjects. The incidence of $\operatorname{IgA}$ deposits in this series $(50 \%)$ is considerably less than that reported by others which varies from 83 to $100 \%$ (Fry and Seah, 1974; Seah and Fry, 1975). However, Jablonska (1976) has stressed the difficulties of the technique, for a second biopsy may be necessary to produce a positive result even after 30 sections have been examined. The fact that only one biopsy from each patient was examined with a maximum of 10 sections may explain the low incidence in our patients. They did, however, have the clinical characteristics, histological features, and response to dapsone which, in the presence of coeliac disease, justifies the diagnosis of dermatitis herpetiformis (Alexander, 1975). Furthermore the lack of correlation in the present series between the presence of IgA deposits in the uninvolved skin and the response of the rash to a gluten free diet supports the doubts expressed about this finding being a prerequisite of the diagnosis.

Seventeen $(81 \%)$ of our 21 patients had a significant improvement in their skin rash after at least 
one year on a gluten free diet. Such improvements have, however, been attributed to factors such as the natural remittance of the rash, the variability of dapsone requirements (Marks and Shuster, 1970), improvement in dapsone absorption associated with the improvement of jejunal morphology, and the placebo effect of regular follow-up (Marks and Whittle, 1969). However, none of these factors appeared to play a part in this series. Thus spontaneous remission had not been noted before the diet and two noticed recurrence of rash after lapses with diet. All seven patients with reduced dapsone dosage noticed that the rash was easier to control and with less variation in dose while on a gluten free diet. Regular follow-up and surveillance had done no good to the patients before diet or to those four who did not respond to diet. Finally, Alexander et al. (1970) found no difference in dapsone absorption between patients on a gluten containing or a gluten free diet.

The improvement in the skin rash was unrelated to the state of the jejunal mucosa before the start of the diet. The one patient with the grade I biopsy before the diet lost the rash completely on the diet and, when biopsied during the diet, while there was no change in morphological grading, did show a dramatic fall in epithelial lymphocytes as has been described by Fry et al. (1972).

All those whose skin responded to the diet showed some morphological improvement in their jejunal mucosa but there was no correlation between the degree of improvement of the skin and the degree of recovery of the jejunal mucosa. Some excellent skin responders had a grade II biopsy while some partial skin responders had a grade I biopsy. Fry et al. (1973) stressed the importance of the length of time on diet for an optimal response. In our series the responders had been on the diet longer than the four nonresponders, but there was no difference in time on the diet between the excellent and partial responders.

Marks and Whittle (1969) noted 10 of 21 patients showed morphological improvement in the jejunal mucosa but they did not link skin response and the state of the jejunal mucosa in the individual patients. This was done by Fry et al. (1969) who studied seven patients of whom three had abnormal biopsies and improved on a gluten-free diet. Taking the whole group, there was an increase in the mean height of the villi and of the surface epithelium together with a decrease of crypt height and a reversal of this improvement when gluten was reintroduced. All the patients except one showed a marked improvement, either losing their skin rash or showing a significant reduction of dapsone requirements. Weinstein $e t$ al. (1971) reported morphological improvement of the jejunal mucosa after $2 \frac{1}{2}$ to six months on a gluten free diet in six patients with dermatitis herpetiformis with an initial flat biopsy but in only one patient was there any benefit to the skin from the diet. Fry et al. (1973) and Heading et al. (1976) made no reference to the jejunal morphology of their subjects while on a gluten free diet.

Of particular interest are the four patients who have not benefited from the diet. The patient with an initial grade 0 biopsy had no change in jejunal morphology or cellularity on the diet, and therefore had no evidence of an enteropathy despite an HL-A8 phenotype, suggesting that gluten is not a factor in the aetiology of the skin rash in every case. This is at variance with the view of Seah et al. (1976) that there is a conclusive association between the skin lesion in dermatitis herpetiformis and gluten intake. The three other non-responders had grade III biopsies before the diet and repeat biopsies on the diet showed no change in one and improvement to grade II in the other two. The lack of response in these patients may indicate some failure in dietetic control. Nevertheless, the grade II biopsies in these patients show no difference whatsoever from the grade II biopsies of the responders and these patients had been on the diet for as long as some of the responders.

An antireticulin antibody of IgG class has been reported in the serum of $17 \%$ of patients with dermatitis herpetiformis (Seah et al., 1971 ; LancasterSmith et al., 1975), which tended to disappear on a gluten free diet (Lancaster-Smith et al., 1975). In the present series, IgG class antireticulin antibodies were found in the serum of five of the 16 patients tested, all of whom were on a gluten free diet and all but one of whom had an initial grade III biopsy. There was no correlation between skin response to the gluten free diet and the presence of these antibodies in the serum. Seah et al. (1972) have suggested that antireticulin antibody cross-reacts with a component of gluten so that the antireticulin antibody can trap gluten complexes in the skin, thus initiating the skin lesion of dermatitis herpetiformis. The occurrence of antireticulin antibody in the serum of three patients on a gluten free diet who have no skin rash and take no dapsone makes this theory less likely.

In conclusion, the majority of patients with dermatitis herpetiformis can expect their skin rash to improve on a gluten free diet, regardless of pre-diet jejunal histology, but the variable response of the skin in the patients with jejunal improvement on the diet suggests either that gluten is only one factor involved in the aetiology of the rash or that the degree of sensitivity of the rash to gluten varies from individual to individual.

We thank Dr E. A. Fairburn and Dr M. A. Cowan consultant dermatologists to the General Hospital, 
Birmingham, for referring patients to us. B.T.C. is in receipt of a grant from the Central Birmingham Health District Trust Fund.

\section{References}

Alexander, J. O'D. (1975). Dermatitis Herpetiformis. Saunders: London.

Alexander, J. O'D., Young, E., McFadyen, T., Fraser, N. G., Duguid, W. P., and Meredith, E. M. (1970). Absorption and excretion of ${ }^{35} \mathrm{~S}$ dapsone in dermatitis herpetiformis. British Journal of Dermatology, 83, 620-631.

Brow, J. R., Parker, F., Weinstein, W. M., and Rubin, C. E. (1971). The small intestinal mucosa in dermatitis herpetiformis-I. Severity and distribution of the small intestinal lesion and associated malabsorption. Gastroenterology, 60, 355-361.

Ferguson, R., Allan, R. N., and Cooke, W. T. (1975). A study of the cellular infiltrate of the proximal jejunal mucosa in ulcerative colitis and Crohn's disease. Gut, 16, 205-208.

Fry, L., McMinn, R. M. H., Cowan, J. D., and Hoffbrand, A. V. (1968). Effect of gluten free diet on dermatological, intestinal and haematological manifestations of dermatitis herpetiformis. Lancet, 1, 557-561.

Fry, L., McMinn, R. M. H., Cowan, J. D., and Hoffbrand, A. V. (1969). Gluten-free diet and reintroduction of gluten in dermatitis herpetiformis. Archives of Dermatology, 100, 129-135.

Fry, L., and Seah, P. P. (1974). Dermatitis herpetiformis; an evaluation of diagnostic criteria. British Journal of Dermatology, 90, 137-146.

Fry, L., Seah, P. P., McMinn, R. M. H., and Hoffbrand, A. V. (1972). Lymphocytic infiltration of epithelium in diagnosis of gluten-sensitive enteropathy. British Medical Journal, 3, 371-374.

Fry, L., Seah, P. P., Riches, D. J., and Hoffbrand, A. V. (1973). Clearance of skin lesion in dermatitis herpetiformis after gluten withdrawal. Lancet, 1, 288-291.

Heading, R. C., Paterson, W. D., McClelland, D. B. L., Barnetson, R. S. C., and Murray, M. S. M. (1976). Clinical response of dermatitis herpetiformis skin lesions to a gluten-free diet. British Journal of Dermatology, 94, 509514.

Holmes, G. K. T., Asquith, P., Stokes, P. L., and Cooke, W. T. (1974). Cellular infiltrate of jejunal biopsies in adult coeliac disease in relation to gluten withdrawal. Gut, 15, 278-283.

Jablonska, S. (1976). In a discussion on dermatitis herpetiformis at the Proceedings of the Pacific Dermatological Association held at Las Vegas, October 1974. Archives of Dermatology, 112, 395.
Lancaster-Smith, M., Kumar, P., Clark, M. L., Marks, R., and Johnson, G. D. (1975). Antireticulin antibodies in dermatitis herpetiformis and adult coeliac disease. British Journal of Dermatology, 92, 37-42.

Marks, J. (1974). The skin-gut relationship in dermatitis herpetiformis. In Coeliac Disease, pp. 375-379. Edited by W. T. J. M. Hekkens and A. S. Peña. Stenfert Kroese: Leyden.

Marks, J., and Shuster, S. (1970). Dermatitis herpetiformisthe role of gluten. Archives of Dermatology, 101, 452-457.

Marks, J., Shuster, S., and Watson, A. J. (1966). Small bowel changes in dermatitis herpetiformis. Lancet, 2, 1280-1282.

Marks, R., and Whittle, M. W. (1969). Results of treatment of dermatitis herpetiformis with a gluten-free diet after one year. British Medical Journal, 4, 772-775.

Ross, I. N., Thompson, R. A., Montgomery, R. D., and Asquith. P. (1977). Immunoglobulin staining in the skin of patients with gastrointestinal disease: Doubt on the disease specificity and significance of $\mathrm{IgA}$ deposition in D.H. Third International Coeliac Symposium, Galway. pp. 66.

Roy-Choudhury, D. C., Cooke, W. T., Tan, D. T., Banwell, J. G., and Smits, B. J. (1966). Jejunal biopsy-criteria and significance. Scandinavian Journal of Gastroenterology, 1, 57-74.

Roy-Choudhury, D. C., Nicholson, G. I., and Cooke, W. T. (1964). Simple capsule for multiple intestinal biopsy speciments. Lancet, 2, 185-186.

Scott, B. B., Young, S., Rajah, S. M., Marks, J., and Losowsky, M. (1976). Coeliac disease and dermatitis herpetiformis-further studies of their relationship. Gut, 17, 759-762.

Seah, P. P., and Fry, L. (1975). Immunoglobulins in the skin in dermatitis herpetiformis and their relevance in diagnosis. British Journal of Dermatology, 92, 157-166.

Seah, P. P., Fry, L., Hoff brand, A. V., and Holborow, E. J. (1971). Tissue antibodies in dermatitis herpetiformis and adult coeliac disease. Lancet, 1, 834-836.

Seah, P. P., Fry, L., Kearney, J. W., Campbell, E., Mowbray, J. F., Stewart, J. S., and Hoffbrand, A. V. (1976). A comparison of histocompatibility antigens in dermatitis herpetiformis and adult coeliac disease. British Journal of Dermatology, 94, 131-138.

Seah, P. P., Fry, L., Stewart, J. S., Chapman, B. L., Hoff brand, A. V., and Holborow, E. J. (1972). Immunoglobulins in the skin in dermatitis herpetiformis and coeliac disease. Lancet, 1, 611-614.

Shuster, S., Watson, A. J., and Marks, J. (1968). Coeliac syndrome in dermatitis herpetiformis. Lancet, 1, 1101-1106.

Weinstein, W. M., Brow, J. R., Parker, F., and Rubin, C. E. (1971). The small intestinal mucosa in dermatitis herpetiformis. II. Relationship of the small intestinal lesion to gluten. Gastroenterology, 60, 362-369. 